\title{
The Effect of Artificial Fertilizers and Dung on the Numbers of Amoebae in Rothamsted Soils
}

\author{
By B. N. SINGH \\ Department of Soil Microbiology, Rothamsted Experimental Station, \\ Harpenden, Herts
}

\begin{abstract}
SUMMARY: The total numbers (active + cystic) and the numbers of active amoebae in plots treated with complete minerals + ammonium sulphate and with farmyard manure were much higher than in the untreated plots. The complete minerals plot of Barnfield had a just significantly lower total count of amoebae than the farmyard manured plot, although no significant difference existed between the counts of active amoebae. The difference in the numbers of both the total and the active amoebae between the complete minerals and farmyard manure-treated plots on Broadbalk was not significant. No correlation was found between the percentage of organic carbon in the soils and the number of amoebae.
\end{abstract}

The occurrence of amoebae and flagellates in large numbers in a normal soil, both in the active and cystic condition, is well known from the work of Cutler, Crump \& Sandon (1922) and others. Crump (1920) found that in one of the Rothamsted fields (Broadbalk) there were more Protozoa, especially amoebae, in the plot manured with farmyard manure than in the untreated one. It is generally believed that the presence of plenty of organic matter in soil will favour an extensive development of bacteria and fungi, which in their turn will be accompanied by an abundant development of Protozoa and other predators. To test the validity of this belief about amoebae, counts of these organisms were made on nine occasions from three of the plots from Barnfield and on six occasions from similarly treated plots of Broadbalk, Rothamsted. This work was started by Mr A. V. Garcia who made the first three counts given in Table 2 .

\section{Methods}

Twelve 4 in. borings were taken at intervals of about $2 \mathrm{yd}$. in a line across the plot and thoroughly mixed together to form a sample. The samples from the three plots were brought to the laboratory at the same time and passed through a $3 \mathrm{~mm}$. sieve. The numbers of amoebae were estimated by the dilution technique of Singh (1946), eight replicate subsamples being tested from each dilution. Only cultures in which amoebae could be seen by microscopic examination were considered positive.

\section{Statistical analysis of the data}

The analysis of the data in this paper is based on the theory developed by Fisher (cf. Introduction to Fisher \& Yates (1947) and Appendix to Singh (1946)). The theoretical standard error of each count of negative cultures is approximately $\sqrt{ } 8$, and the distribution of the number of cultures may be taken as normal. Hence, ignoring the error due to soil sampling (see below), the $5 \%$ significance level difference between two individual counts is eight cultures, 
corresponding to approximately $100 \%$ difference in population estimates. Since there was a different soil humidity on the different plots a correction was made for this. The estimates of population/g. were adjusted to a dry-weight basis before analysis. The first Barnfield observation contained no measurement of soil moisture and so was rejected.

\section{Count of amoebae from duplicate samples}

Recently it has been claimed by a few workers (see Harmsen, 1940; and references in James \& Sutherland, 1942) that the method of soil sampling and the dilution technique used at Rothamsted and elsewhere for the plate count of bacteria in soil do not give reproducible results when several samples of a soil or different portions of a single soil sample are compared. This has led some to believe that the fluctuations in the numbers of bacteria in soil at short intervals reported from Rothamsted are due to faulty technique and do not really occur in soils in their natural state. It is not intended to discuss the matter here, but it may be pointed out that a few of the classical fields of Rothamsted which have been investigated have given reproducible results in the count of Protozoa and bacteria when several soil samples or fractions of a single sample have been compared by the techniques used at Rothamsted. This may be due to an unusual homogeneity of the soils from the Rothamsted classical fields as a result of similar cultivation and treatments carried out over a very long period. It would be of great interest to compare a variety of different soils to find out whether the elaborate methods of sampling and dilution technique suggested by a few workers are necessary in quantitative studies on soil micro-organisms. It is hoped to follow up this line of investigation.

To test the accuracy of sampling in the count of amoebae by the dilution technique several counts of the total amocbae in duplicate samples were made from different plots of Barnfield and Broadbalk (Table 1). Two samples, A and $B$, were taken at the same time on eight different dates and the number of amoebae determined. The differences between duplicate samples were not significant in any of the comparisons (cf. Singh (1946) for the standard error of such counts). The $\chi^{2}$ test on these differences reveals no more variation than may be expected from the dilution method.

\section{Comparison of the numbers of amoebae in three different plots on Barnfield and on Broadbalk, Rothamsted}

The three plots selected from Barnfield (permanent mangolds) were: plot $8 \cdot 0$, untreated; plot $1 \cdot 0$, receiving 14 tons of dung/acre/year; plot $4 \mathrm{~A}$, receiving a dressing of complete minerals ( $3 \frac{1}{2} \mathrm{cwt}$. of superphosphate, $500 \mathrm{lb}$. of potassium sulphate, $200 \mathrm{lb}$. of sodium chloride and $200 \mathrm{lb}$. of magnesium sulphate) and $\$ 12 \mathrm{lb}$. of ammonium sulphate/acre/year. These plots have been treated in the same way since 1876. Three similar plots were selected from Broadbalk (permanent wheat): plot 3, untreated; plot 2, receiving 14 tons of dung/acre/year;

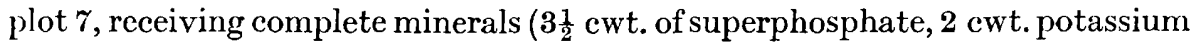


sulphate, 1 cwt. sodium sulphate and 1 cwt. magnesium sulphate), and 4 cwt. of ammonium sulphate/acre/year. Plot 3 has been unmanured since 1839. Wheat has been grown continuously in each of the three plots since 1852, and the fertilizer treatments have been the same each year.

Table 1. The total counts of amoebae (active+cystic) found when two samples were taken at the same time from Barnfield or Broadbalk plots

F.Y.M. = farmyard-manured plot; C.M. = complete minerals + ammonium sulphate plot; $\mathbf{U} .=$ untreated plot; $\Delta=$ difference in number of negative cultures between samples $\mathbf{A}$ and $\mathbf{B}$.

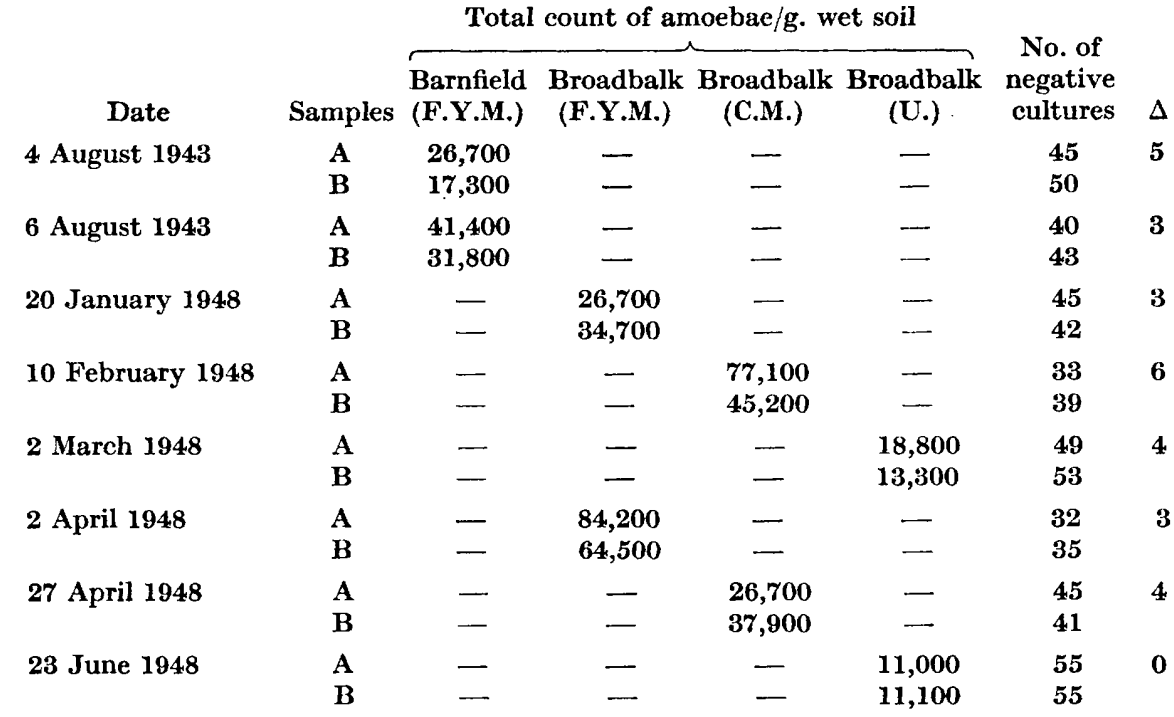

Table 2 shows the results obtained from Barnfield plots. The total and the active counts of amoebae are very much lower in the untreated plot than in either the farmyard manured or the complete minerals + ammonium sulphate plots. Total counts (active + cystic amoebae) in the latter plots did not differ significantly from those in the farmyard-manured plot on any occasion. When the eight counts are taken together the farmyard-manured plot has about $30 \%$ higher count of amoebae, the difference being just significant at the $5 \%$ level. The differences between counts of active amoebae in the minerals and farmyard-manured plots were not significant, with the exception of one observation.

Table 3 shows the counts of amoebae taken on six occasions from the three corresponding plots of Broadbalk. Both the total and the active counts in the untreated plot are again very much lower than in the other two plots. The total counts in the farmyard-manured and complete-minerals plot did not differ significantly on five occasions, but on one occasion the farmyard plot had a significantly higher number. When all the counts are taken together, the farmyard plot has about $\mathbf{5 0} \%$ higher total count, this difference not being statistically significant. Similarly, in the active counts there are no significant differences either on individual occasions or in the means of all the counts. 

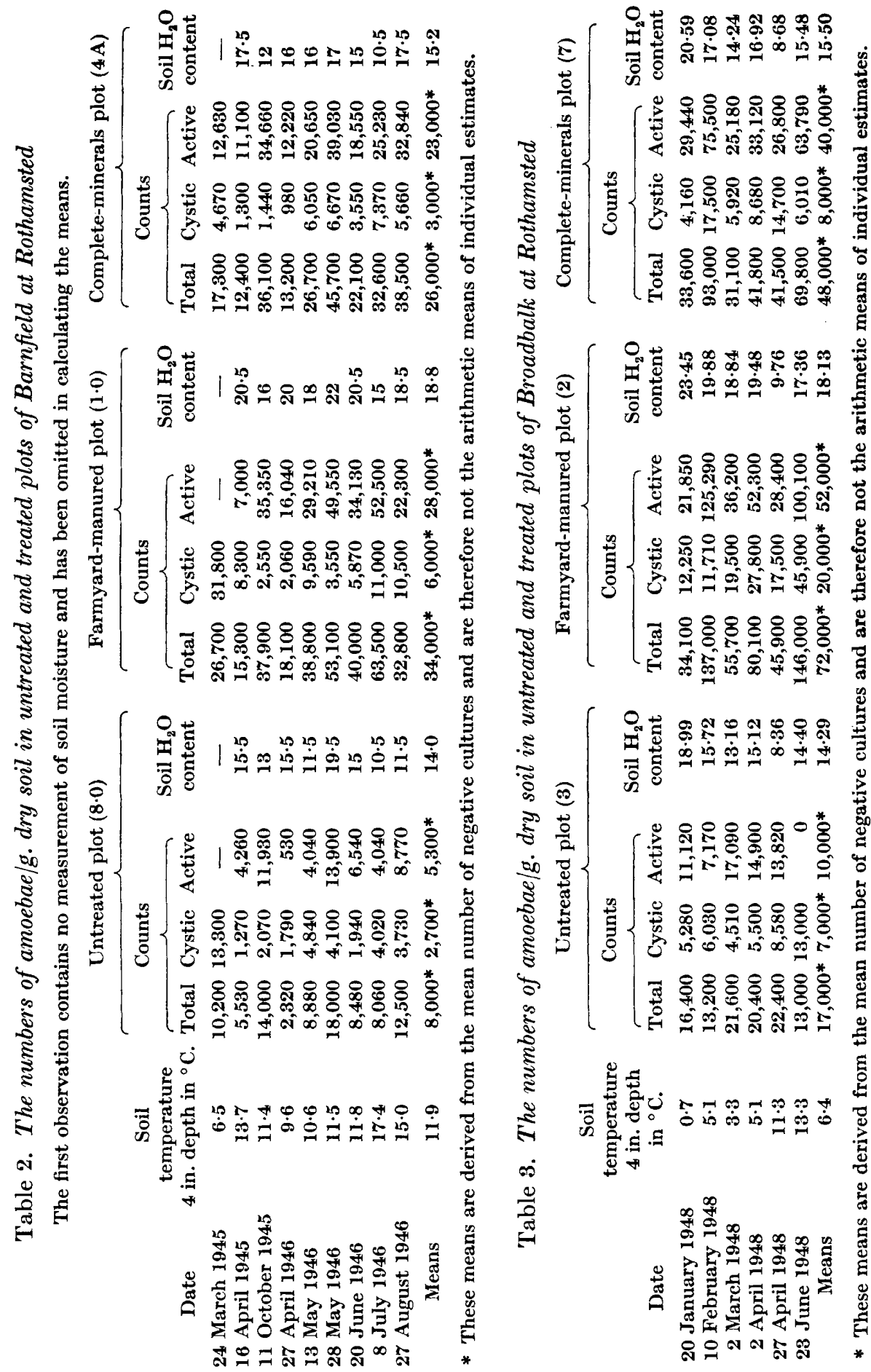
In general the results on Broadbalk confirmed those from Barnfield in spite of a much higher population in the former. The following conclusions may thus be drawn with some confidence. Although the percentage of organic carbon is roughly the same in the untreated and complete-minerals plots of Barnfield and Broadbalk, the number of amoebae in the untreated plots is much lower than in the complete-minerals plots. The differences in the total counts as

Table 4. The $\mathrm{pH}$ values and organic matter content of the soils in the different plots of Barnfield and Broadbalk at Rothamsted.

$2 \mathrm{~mm}$. air-dry soil was used to determine the percentage of organic content of the soils

\begin{tabular}{lcc}
\multicolumn{1}{c}{ Plot } & pH value & $\%$ \\
Barnfield & & \\
Untreated (plot 8.0) & $\mathbf{7 \cdot 2}$ & $0 \cdot 8$ \\
Complete minerals (plot 4 A) & $\boldsymbol{7 \cdot 1}$ & $\mathbf{0 \cdot 8}$ \\
Farmyard manured (plot 1.0) & $\mathbf{7 \cdot 0}$ & $\mathbf{2 \cdot 5}$ \\
Broadbalk & & \\
Untreated (plot 3) & $\mathbf{8 \cdot 1}$ & $\mathbf{1 \cdot 1}$ \\
Complete minerals (plot 7) & $\mathbf{7 \cdot 9}$ & $\mathbf{1 \cdot 2}$ \\
Farmyard manured (plot 2) & $\mathbf{7 \cdot 7}$ & $\mathbf{2 \cdot 6}$
\end{tabular}

between the complete-minerals plots and the farmyard-manured ones are not statistically significant in the Broadbalk observations, and just reach significance in the case of Barnfield, in spite of large differences in the organic matter contents between these two soils (Table 4). The differences between counts of active amoebae are not significant.

It is of interest that the yields of mangolds and wheat in the untreated plots are about one-third those of the farmyard manure or the complete-minerals plots, as are also the numbers of amoebae in these plots. No marked differences are found in the yields of the plots treated with farmyard manure or with complete minerals + ammonium sulphate. Thus the crop yields and the population of amoebac are correlated in both fields. It may be emphasized that the treatment of the soil with artificial fertilizers for a long time has had no detrimental effect on the amoebae, but has in fact much increased their numbers in comparison with those in the untreated plot.

\section{DISCUSSION}

It has been claimed by some earlier workers that the numbers of Protozoa, especially amoebae, in soil is insufficient to cause changes in the bacterial population. Daily estimates made by Cutler et al. (1922) over a period of 365 days, however, indicated amoebae in numbers which, in view of their food requirements, must greatly affect bacterial numbers. Indeed, these authors obtained evidence of an inverse relationship between the numbers of active amocbae and those of bacteria as shown by plate counts. Improved technique (Singh, 1946) has since shown that the numbers of amoebae were previously underestimated. Soil amoebae and other groups of micropredators are selective in their bacterial food requirements on non-nutrient agar 
(Singh, 1941, 1942, 1945, 1946, 1947 $a, b, c, 1948$ ). Differential feeding effects for certain strains of bacteria have also been shown to occur in sterilized soil both with true soil amoebae and with myxamoebae of Acrasieae (Singh, 1941, $1947 c$ ). This work suggests that the micropredators may also affect the quality of the bacterial population, or conversely that their numbers may be affected by the proportion of edible bacteria present in soil.

The present work shows that the differences in the numbers of active amoebae as between the complete minerals and the farmyard-manured plots of Barnfield and Broadbalk are not statistically significant. Parallel estimates, however (unpublished), have shown that the bacterial populations of farmyardmanured plots are higher than those in the complete-minerals plots, at least as estimated by plate counts. Thus it seems that some other factor, such as the quality of the bacterial flora, must account for the different relative effect of manurial treatment on bacteria and amoebae respectively.

This work was made possible by a grant from the Agricultural Research Council to whom the author's thanks are due. I am very grateful to Mr A. V. Garcia (British Council Scholar at Rothamsted) for making the first three counts in Table 2. My thanks are also due to Mr Warren of the Chemistry Department for determining the organic matter contents and $\mathrm{pH}$ of the soils and to $\mathrm{Mr}$ G. Paine for kindly carrying out the statistical analysis. It is a pleasure to express my sincere thanks to Dr H. G. Thornton, F.R.S., and Miss L. M. Crump for their interest in this work.

\section{REFERENCES}

Crump, L. M. (1920). Numbers of Protozoa in certain Rothamsted soils. J. agric. Sci. 10, 182.

Cutler, D. W., Cremp, L. M. \& Sandon, H. (1922). A quantitative investigation of the bacterial and protozoan population of the soil, with an account of the protozoan fauna. Philos. Trans. B, 211, 317.

Fismer, R. A. \& Yates, F. (1947). Statistical Tables for Biological, Agricultural and Medical Research, 3rd ed. London: Oliver and Boyd.

Harmsen, G. W. (1940). The influence of the method of sampling on the accuracy of the determination of bacterial numbers in soil. Antonie van Leeuwenhoek. J. Microbiol. serol. 6, 178.

James, N. \& Sutherland, M. L. (1942). Individual plot studies of variation in numbers of bacteria in soil. II. The errors of the procedure. Canad. J. Res. C, 16, 305 .

SiNGH, B. N. (1941). Selectivity in bacterial food by soil amoebae in pure mixed cultures and in sterilized soil. Ann. appl. Biol. $28,52$.

Singri, B. N. (1942). Selection of bacterial food by soil flagellates and amoebae. Ann. appl. Biol. 29, 18.

SiNGH, B. N. (1945). The selectivity of bacterial food by soil amoebae, and the toxic effects of bacterial pigments and other products on soil protozoa. Brit. J. exp. Path. 26, 316.

SINGII, B. N. (1946). A method of estimating the numbers of soil protozoa, especially amoebae, based on their differential feeding on bacteria. Ann. appl. Biol. 33, 112.

SINGII, B. N. (1947a). Myxobacteria in soils and composts; their distribution, number, and lytic action on bacteria. J. gen. Microbiol. $1,1$. 
SiNGH, B. N. (1947b). Studies on soil Acrasieae. 1. Distribution of species of Dictyostelium in soils of Great Britain and the effect of bacteria on their development. J. gen. Microbiol. $1,11$.

Singh, B. N. (1947c). Studies on soil Acrasieae. 2. The active life of Dictyostelium in soil and the influence thereon of soil moisture and bacterial food. J. gen. Microbiol. 1, 361.

Singh, B. N. (1948). Studies on giant amoeboid organisms. 1. The distribution of Leptomyxa reticulata Goodey in soils of Great Britain and the effect of bacterial food on growth and cyst formation. J. gen. Microbiol. 2, 8.

(Received 3 August 1948) 